\title{
The wasp larva's last supper: 100 million years of evolutionary stasis in the larval development of rhopalosomatid wasps (Hymenoptera: Rhopalosomatidae)
}

\author{
Volker Lohrmann ${ }^{1,2}$ and Michael S. Engel ${ }^{3,4}$ \\ ${ }^{1}$ Übersee-Museum Bremen, Bahnhofsplatz 13, 28195 Bremen, Germany \\ ${ }^{2}$ Museum für Naturkunde, Leibniz-Institut für Evolutions- und Biodiversitätsforschung, Invalidenstraße 43, 10115 Berlin, \\ Germany \\ ${ }^{3}$ Division of Entomology, Natural History Museum, and Department of Ecology \& Evolutionary Biology, 1501 Crestline \\ Drive - Suite 140, University of Kansas, Lawrence, Kansas 66045-4415, USA \\ ${ }^{4}$ Division of Invertebrate Zoology, American Museum of Natural History, Central Park West at 79th Street, New York, New \\ York 10024-5192, USA \\ Correspondence to: Volker Lohrmann (v.lohrmann@uebersee-museum.de)
}

Received: 24 May 2017 - Revised: 13 July 2017 - Accepted: 17 July 2017 - Published: 25 August 2017

\begin{abstract}
Rhopalosomatidae are an unusual family of wasps (Hymenoptera: Aculeata) comprising less than 100 species found in the tropics and subtropics of all continents except Europe and Antarctica. Whereas some species resemble nocturnal Ichneumonidae, others might be mistaken for spider wasps or different groups of brachypterous Hymenoptera. Despite their varied morphology, all members of the family supposedly develop as larval ectoparasitoids of crickets (Orthoptera: Grylloidea). Here, we report on the first record of a fossil rhopalosomatid larva which was discovered in midCretaceous amber from northern Myanmar (Burma). The larva is attached to the lateral side of a cricket between the metafemur and the abdomen, impacting the natural position of the hind leg, exactly as documented for modern species. Additionally, the larval gestalt is strikingly similar to those of extant forms. These observations imply that this behavioral specialization, e.g., host association and positioning on host, likely evolved in the stem of the family at least 100 million years ago.
\end{abstract}

\section{Introduction}

Rhopalosomatidae are a family of aculeate wasps that as larvae are ectoparasitoids of crickets and are distributed predominantly pantropically. The family comprises 72 extant and 4 extinct species described in four Recent and four fossil genera, respectively (Aguiar et al., 2013). In Southeast Asia, where this fossil was found, the family is currently represented by only seven formally described species assigned to two genera: Liosphex trichopleurum Townes, Paniscomima abnormis Townes, $P$. angelae Guidotti, $P$. darlingi Guidotti, P. lottacontinua Guidotti, P. opposita Townes, and P. paropposita Guidotti (Guidotti, 2007; Lohrmann and Ohl, 2010; Lohrmann, 2011). Whereas L. trichopleurum is reported from the islands of Mindanao and Borneo, the species of Paniscomima Enderlein are described from the mainland with records from India to Vietnam. To this diversity might be added a third genus, Olixon Cameron, which is known from Asia only by a single unidentified specimen from India, and which remains to be formally treated (Guidotti, 1999; pers. obs.).

Data on the biology of the family are scarce. As far as is known, the larvae of rhopalosomatid species (Fig. 1) are ectoparasitoids of crickets (Orthoptera) (e.g., Perkins, 1908; Gurney, 1953; Lohrmann et al., 2014). Yet few data have been published on their host-parasite relationships. As it concerns the Recent fauna, Rhopalosoma nearcticum Brues has been associated with species of the hapithine genera Hapithus Uhler and Orocharis Uhler (Hood, 1913; Gurney, 1953; Townes 1977), while Olixon australiae (Perkins) has been reared from an unidentified trigonidiine cricket 

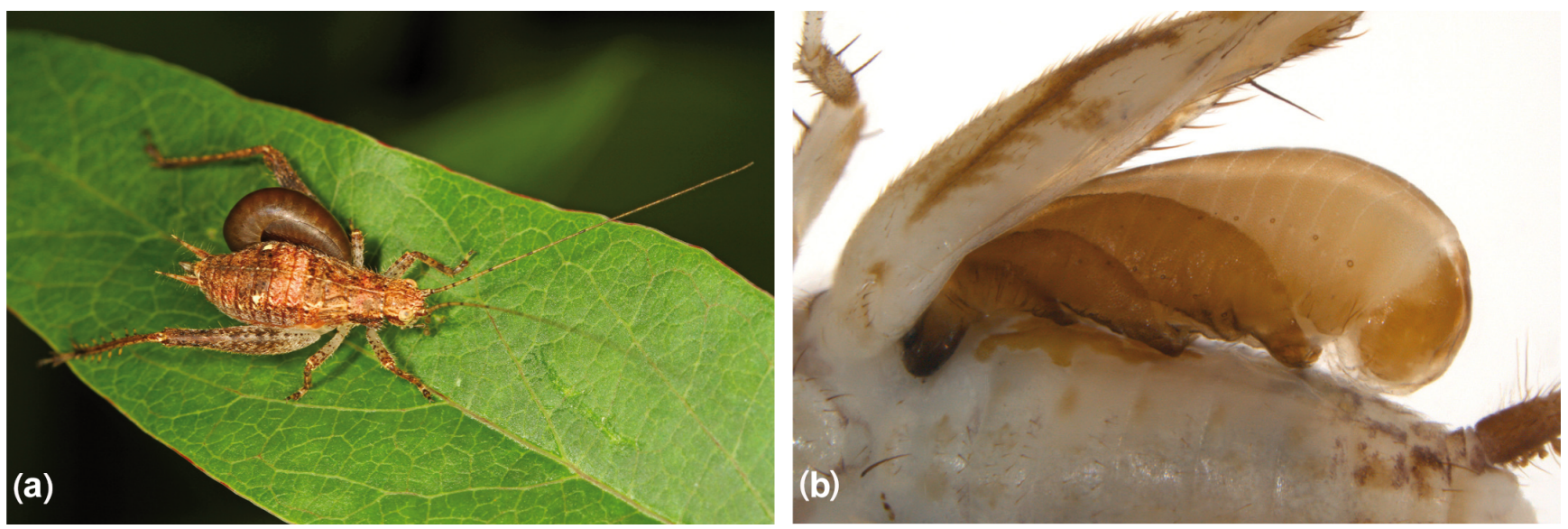

Figure 1. Recent rhopalosomatid larvae parasitizing crickets (Grylloidea). (a) Hapithine cricket with a rhopalosomatid larva (putatively Rhopalosoma nearcticum Brues), photographed in Virginia, USA. Photo: Judy Gallagher, CC-BY-2.0, originally posted to Flickr. (b) Rhopalosomatid larva, fourth instar (Olixon? sp.), parasitizing a nemobiine cricket, collected in Florida, USA; deposited in the personal collection of Volker Lohrmann.

(Perkins, 1908). Townes (1977) suggested the genera Cycloptilum Scudder and Nemobius Audinet-Serville as hosts for the American O. testaceum Cameron and O. banksii Brues, respectively, but only the latter relationship received additional support by the recent discovery of a female of $O$. banksii attacking a nemobiine cricket for oviposition (Lohrmann et al., 2014; as mentioned there, Townes was likely referring to a member of either Allonemobius Hebard, Eunemobius Hebard, or Neonemobius Hebard since Nemobius, as currently understood, is not a New World genus).

Larval development has been elaborated only for $R$. nearcticum, first reported by Hood (1913) and then more fully complemented with detailed morphological characterizations of the egg and larval instars by Gurney (1953). Gurney noted that the egg and exuvium of the first instar were positioned directly behind the host's metacoxa, while the second through fourth larval instars were attached to the lateral surface of the cricket's abdomen. Owing to the growing size of the larva, the host's leg was forced outward into a distinctly unnatural position (Gurney, 1953). The larva remained on the host until the fifth instar emerged, at which time it left the host, which had died moments before, and burrowed into the soil, where it spun a cocoon, pupated, and emerged as an adult the following year (Hood, 1913; Gurney, 1953). The position of the egg and larva behind the metacoxa and then on the lateral abdominal wall behind the leg presumably prevent the parasitoid from being dislodged by the host, although it remains unclear to what extent the host's usual behavior and biology or how its ability to walk or jump are influenced by the presence of the developing wasp - the mating behavior, however, seems to be unaffected (Alexander and Otte, 1967). Regardless, the position of the immature wasps on their cricket hosts is quite distinctive.
Until now, only four fossil species have been formally described and assigned to the family (Darling and Sharkey, 1990; Dlussky and Rasnitsyn, 1999; Engel, 2008; Nel et al., 2010). Whereas the descriptions of three of these taxa are based on poorly preserved compression fossils that may not belong to the family, Eorhopalosoma gorgyra Engel is not only based on a complete inclusion preserved in midCretaceous Burmese amber, but it is the sole fossil that can be assigned definitively to the family (Engel, 2008; pers. obs.).

During recent surveys of fossil inclusions, an almost completely preserved cricket was discovered in Burmese amber; it has a late-instar rhopalosomatid larva attached to the lateral abdominal wall immediately behind the hind leg, resulting in the characteristically awkward protrusion of the leg obliquely away from the body. This represents the first discovery of immature vespoid parasitoids from the Mesozoic and reveals a considerable constancy in rhopalosomatid biology over the last 100 million years.

\section{Materials and methods}

Both the cricket and wasp are excellently preserved in a polished piece of amber of about $1.32 \mathrm{~cm} \times 1.27 \mathrm{~cm} \times 0.55 \mathrm{~cm}$, and with considerable clarity and minimal debris. The amber originates from mines in the Hukawng Valley of Kachin State, northern Myanmar (formerly Burma). The age and origin of Burmese amber has been reviewed by Zherikhin and Ross (2000), Grimaldi et al. (2002), Cruickshank and Ko (2003), and Ross et al. (2010) but most recently has been established as approximately $98 \mathrm{Ma}$ based on radiometric dating of zircons (Shi et al., 2012), thereby placing the fauna at the base of the Cenomanian and near the Albian boundary (mid-Cretaceous). 
The amber piece is currently deposited in the private collection of the first author until the final repository has been clarified. The inclusions were studied and measured with a Zeiss ${ }^{\circledR}$ SteREO Discovery.V20 microscope with an ocular micrometer. Photographs of the fossil were taken using a Canon EOS 6D digital camera either with a Leitz Photar $25 \mathrm{~mm} \mathrm{f} / 2.0$ lens or with a Canon MP-E $65 \mathrm{~mm} \mathrm{f} / 2.8$ lens in combination with the software program Helicon Remote and later stacked with the software program Helicon Focus Pro.

The terminology of the larval morphology has been adopted from Gurney (1953). The descriptive notes of the cricket are based on (sub-)family-level key characters extracted from Otte and Alexander (1983) and Walker (2017). With respect to the classification of Orthoptera, we follow Cigliano et al. (2017).

\section{Systematic paleontology}

Order Hymenoptera Linnaeus, 1758

Family Rhopalosomatidae Ashmead, 1896

Fourth-instar larva

(Fig. 2)

Description: The larva, which is a fourth instar, is about $3.7 \mathrm{~mm}$ long and $1.4 \mathrm{~mm}$ high, and matches in almost every detail observable the larva described for Rhopalosoma nearcticum (Gurney, 1953). It is attached to the left side of the cricket between the metafemur and the abdomen, and is of almost equal size to the latter. The head is well defined by a constriction separating it from the rest of the body which is of paler coloration. The mandibles are largely concealed by the labrum and ventrally flanked by the maxillae. Further details of the mouthparts, e.g., whether the mandibles have a row of minute teeth on the inner apical margins, comparable to those described by Gurney, cannot be observed since the mouthparts can be studied from the lateral view only. The body segments are less clearly defined by weak constrictions. The lateral spiracles are very distinct and about $0.02 \mathrm{~mm}$ wide (max. diameter). Unfortunately, the full number of spiracles cannot be observed due to preservation artefacts. However, the exuviae of the third instar (and so likely also the fourth instar) have ten spiracles, similar to the fourth and fifth instars of $R$. nearcticum described by Gurney. Of the first two spiracles Gurney describes one as situated "on the posterior third of the prothorax" whereas the second lies "barely anterior to the groove separating mesoand metathorax". This description also seems to match the larva described herein although the grooves separating the thoracic segments are quite indistinct due to slight shrinking artefacts. The spiracles on abdominal segments 1-8, are situated slightly more dorsad than the thoracic ones and near the anterior margin of the respective segment. As described by Gurney for the fourth instar, the microstructure of the dorsal and lateral integument has the appearance of being "covered with closely appressed scales" resembling a dried, empty snake skin. Clearly visible are the "closely appressed" exuviae of the preceding three instars (as also observed for R. nearcticum: Gurney, 1953) which are still flanking the posterior part of the larva and which are split lengthwise on the dorsum over the complete length. The exuviae are about $0.6,1.5$, and $2.5 \mathrm{~mm}$ long, respectively. Each instar (or its exuviae) is of slightly paler coloration than the preceding exuviae. This certainly does not reflect the real coloration but is an artefact of the multiple layers of exuviae absorbing more light. While the caudal end of the larva remains in the same position throughout the four instars, the head shifted progressively caudad on the cricket from instar to instar and as each stage needed to expand away from the exuviae being shed.

Remarks: The host is a male cricket of the family Gryllidae. However, based on the observable characters we are currently unable to properly assign the specimen to any of the known subfamilies. The cricket is almost completely preserved except for parts of the antennae and the tip of the left pretarsal claw. The left hind leg is protruded at an unnatural, awkward angle away from the body owing to the large wasp larva forcing it outward into this position.

Descriptive notes on host. About $6.0 \mathrm{~mm}$ long (excluding antennae and cerci). Head including compound eyes about as wide as pronotum, not prognathous, and with dorsal bristles. Compound eyes not reduced, with more than 50 facets, together forming a smoothly rounded convex surface. Antenna inserted at middle of the face between ventral regions of the compound eyes. Clypeus unspecialized, not extending onto dorsum of head. Wings absent. Forelegs slender, not enlarged and shovel-like for digging. Metafemur about one-sixth as wide as long and as long as metatibia. Tibiae not quadrate but rather rounded in cross section. Metatibia with two rows of subapical spurs on upper inner and outer margins and with small spines in between, inner margin with 11, outer with 6 (or 7?) subapical spines. Tarsi with three tarsomeres. Metabasitarsus without dorsal rows of denticles or nonapical dorsal spurs. Tarsomere II unspecialized, not flattened and without prominent ventral tuft of setae or adhesive pads. Pretarsal claws simple. Body not covered with scales.

\section{Discussion}

Orthopteran fossils are not commonly found in amber (Heads, 2009), and such scarcity is even more pronounced for fossils of Rhopalosomatidae. Moreover, fossils of immature aculeate Hymenoptera are exceptionally rare, particularly when in association with their host or prey. It is therefore remarkable to discover a confluence of rarities within a single inclusion and one of sufficient geological age as to be 

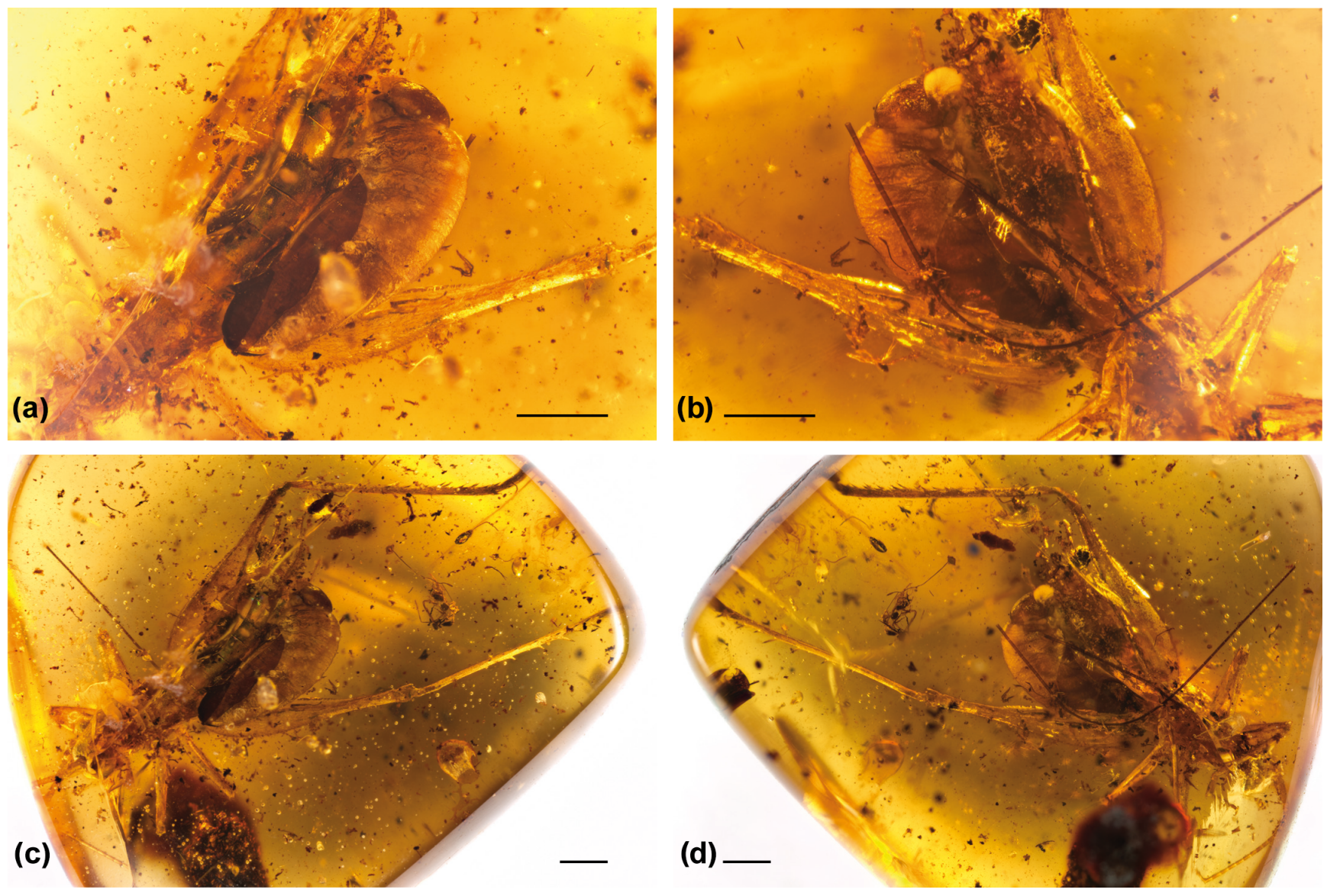

Figure 2. Gryllidae with a rhopalosomatid larva in mid-Cretaceous Burmese amber. (a) Close-up of the larva (seen from left side). (b) Close up of the larva (seen from right side). (c) Dorsal view of the cricket with rhopalosomatid larva. (d) Ventral view of the cricket with rhopalosomatid larva. Scale bars: $1 \mathrm{~mm}$. Photos: Johann Hendrik Nüß.

fairly close to the radiation of the Euaculeata (Grimaldi and Engel, 2005; Wilson et al., 2013; Branstetter et al., 2016). Adult rhopalosomatids, while rare, have been discovered in amber (Engel, 2008), and more than 15 specimens have been assembled from Burmese, Dominican, and Mexican ambers, the latter two deposits of Early Miocene age (pers. obs.). Collectively, these adults and the present larva demonstrate considerable longevity for the family.

Considering the fact that the larval exoskeleton of aculeates is comparably weakly sclerotized, the excellent preservation of the larva is remarkable and due solely to the fidelity permitted by inclusion in amber. Such preservation enables confident placement as to family, particularly considering the unique position of the larva on its host. Unfortunately, given that the larval stages of only $R$. nearcticum have been described among the modern fauna, it is impossible to know what diagnostic characters distinguish the various species or genera of the family. Furthermore, in the absence of such information coupled with both a particular host and associated adults, it remains to be discovered what characters permit positive species identification and association between larval, pupal, and adult stages for these wasps. Thus, while it is tantalizing to consider the present larva as the immature form of E. gorgyra in the same amber deposit, such a specific association cannot be defended. Nonetheless, it is significant that rhopalosomatids have now been discovered as both adults and immatures from a single deposit in the Cretaceous and victimizing the same family of hosts as their modern relatives.

Among hymenopteran ectoparasitoids of Grylloidea, only the Rhopalosomatidae oviposit without moving the host from the position at which it was attacked. This combination, i.e., host specificity and lack of host relocation, is not only characteristic for the group but also unique among Hymenoptera (e.g., Brothers and Carpenter, 1993; Melo et al., 2011). Where known, the ectoparasitoid larvae of Dryinidae (Chrysidoidea) are quite similar in general appearance (Brues, 1943) but are specialized to develop strictly on leafhoppers or, more rarely, treehoppers (Auchenorrhyncha) (Olmi et al., 2014). Moreover, dryinid larvae, which have the head embedded within the host's body (dryinids initiate development as endoparasitoids before extruding as ec- 
toparasitoids for the remainder of their ontogeny), form a characteristic thylacium - a protective layer formed from the shed exuviae. Different groups of apoid wasps, e.g., species of the genera Sphex Linné, Larra Fabricius, Liris Fabricius, Tachysphex Kohl, or Tachytes Panzer, prey solely on Orthoptera. However, with exceptions, e.g., Larra spp., all of these predatory species paralyze their prey and relocate the immobilized victim to a newly constructed or pre-existing burrow before depositing an egg (Bohart and Menke, 1976; O'Neill, 2001; Melo et al., 2011). The relocation to a concealed nest certainly minimizes the pressure from subsequent predation, such as by birds, and might be one of the reasons why these groups, though perhaps of a younger geological age, became much more diverse. Species of the genus Larra do not relocate their victims, but a similar benefit is received through host choice, as they are ectoparasitoids of mole crickets (Gryllotalpidae) (O'Neill, 2001), which are attacked in their burrows and which, as their name suggests, spend most of their life in subterranean tunnels and therefore mimic the nests dug by the aforementioned apoid wasps. Among aculeate wasps, the exposed development of an ectoparasitoid larva on Grylloidea is a presumably relict biology of Rhopalosomatidae.

The overall similarities between Recent and the present fossil rhopalosomatid larvae (cf. Figs. 1, 2) along with identical placement on the same host family suggest that host association and larval development in Rhopalosomatidae have remained comparatively static during much of the last 100 million years. They also imply, indirectly, that a similar behavior was likely present among adult females for manipulating and ovipositing on the host. The present fossil effectively demonstrates a conservatism and persistence of general behavior and development (ethological and ontological stasis) within the lineage and despite considerable cladogenesis in the hosts along with changes in climate and habitat since the Cenomanian. Typically, one thinks of morphological conservatism (bradytely) as the result of consistent microhabitats through time, such as living subcortically (e.g., Hamilton, 1978; Chatzimanolis et al., 2013; Engel et al., 2016), and a similar constancy is required in order to maintain such behaviors and biologies over vast expanses of time, through episodes of considerable climatic and biotic change, as well as continued cladogenesis among the hosts. Endoparasitoids, of course, develop within an obviously analogous "subcortical" microhabitat, but the exposed larvae of ectoparasitoids may likely be perceived in the same manner. Constancy in the development, physiology, and biology of the host may provide sufficient stability to maintain conservatism within the ectoparasitoid, particularly when there may be a lack of one-to-one specificity between the host and parasite, as is seemingly the case among rhopalosomatids. It therefore appears that the unique biology of rhopalosomatids was established by the Early Cretaceous and may be characteristic of the stem group, particularly if it may eventually be demon- strated that Mesozoic Rhopalosomatidae belong outside of the crown group.

Data availability. No data sets were used in this article.

Competing interests. Volker Lohrmann and editor Florian Witzmann are affiliated with the same institution, i.e., Volker Lohrmann is a visiting scientist at the MfN, but they do not collaborate scientifically. The paper was accepted on the basis of reviews from two outside reviewers. The authors declare no other competing interests.

Acknowledgements. We are sincerely thankful to Johann Hendrik Nüß (Bremen) for taking the photographs of the fossil, Judy Gallagher (Woodbridge, Virginia) for her kind permission to use photograph 1a, and Inge Wulfken-Jung (Bremen) for preparing the two photo plates. Furthermore, we thank Mark Deyrup (Archbold Biological Station, Florida) for granting to Volker Lohrmann the rhopalosomatid larva illustrated in Fig. 1b. Finally, we thank Denis J. Brothers and an anonymous reviewer for their valuable comments on the manuscript. This is a contribution of the Division of Entomology, University of Kansas Natural History Museum.

Edited by: Florian Witzmann

Reviewed by: Denis J. Brothers and one anonymous referee

\section{References}

Aguiar, A. P., Deans, A. R., Engel, M. S., Forshage, M., Huber, J. T., Jennings, J. T., Johnson, N. F., Lelej, A. S., Longino, J. T., Lohrmann, V., Mikó, I., Ohl, M., Rasmussen, C., Taeger, A., and Yu, D. S. K.: Order Hymenoptera, Zootaxa, 3703, 51-62, https://doi.org/10.11646/zootaxa.3703.1.12, 2013.

Alexander, R. D. and Otte, D.: Cannibalism during copulation in the brown bush cricket, Hapithus agitator (Gryllidae), Fla. Entomol., 50, 79-87, 1967.

Bohart, R. M. and Menke, A. S.: Sphecid wasps of the world: a generic revision, University of California Press, Berkeley, 1976.

Branstetter, M. G., Danforth, B. N., Pitts, J. P., Faircloth, B. C., Ward, P. S., Buffington, M. L., Gates, M. W., Kula, R. R., and Brady, S. G.: Phylogenomic analysis of ants, bees and stinging wasps: improved taxon sampling enhances understanding of Hymenopteran evolution, Curr. Biol., 27, 1019-1025, https://doi.org/10.1016/j.cub.2017.03.027, 2016.

Brothers, D. J. and Carpenter, J. M.: Phylogeny of Aculeata: Chrysidoidea and Vespoidea, J. Hym. Res., 2, 227-304, 1993.

Brues, C. T.: The American species of Rhopalosoma, Ann. Entomol. Soc. Am., 36, 310-318, 1943.

Cigliano, M. M., Braun, H., Eades, D. C., and Otte, D.: Orthoptera Species File, Version 5.0/5.0, available at: http://Orthoptera. SpeciesFile.org (last access: 15 May 2017), 2017.

Chatzimanolis, S., Newton, A. F., Soriano, C., and Engel, M. S. Remarkable stasis in a phloeocharine rove beetle from the Late Cretaceous of New Jersey (Coleoptera, Staphylinidae), J. Paleontol., 87, 177-182, 2013. 
Cruickshank, R. D. and Ko, K.: Geology of an amber locality in the Hukawng Valley, northern Myanmar, J. Asian Earth Sci., 21, 441-455, https://doi.org/10.1016/S1367-9120(02)00044-5, 2003.

Darling, D. C. and Sharkey, M. J.: Order Hymenoptera edited by: Grimaldi, D. A., Insects from the Santana Formation, Lower Cretaceous, of Brazil, Bulletin of the American Museum of Naturel History, 195, 209-229, 1990.

Dlussky, G. M. and Rasnitsyn, A. P.: Two new aculeate hymenopterans (Vespida $=$ Hymenoptera) from the Middle Eocene of United States, Paleontologicheskii Zhurnal, 5, 72-75, 1999 (in Russian; English translation in: Paleontological Journal, 33, 546-549).

Engel, M. S.: The wasp family Rhopalosomatidae in Mid-Cretaceous amber from Myanmar (Hymenoptera: Vespoidea), J. Kans. Entomol. Soc., 81, 168-174, https://doi.org/10.2317/JKES-712.11.1, 2008.

Engel, M. S., Breitkreuz, L. C. V., Cai, C., Alvarado, M., Azar, D., and Huang, D.: The first Mesozoic microwhip scorpion (Palpigradi): a new genus and species in mid-Cretaceous amber from Myanmar, Sci. Nat., 103, 19, 2016.

Grimaldi, D. and Engel, M. S.: Evolution of the Insects, Cambridge Univ. Press, Cambridge, 2005.

Grimaldi, D., Engel, M. S., and Nascimbene, P.: Fossiliferous Cretaceous amber from Myanmar (Burma): its rediscovery, biotic diversity, and paleontological significance, Am. Mus. Novit., 3361, 1-72, https://doi.org/10.1206/00030082(2002)361<0001:FCAFMB>2.0.CO;2, 2002.

Guidotti, A. E.: Systematics of little known parasitic wasps of the family Rhopalosomatidae (Hymenoptera: Vespoidea), M.Sc. Thesis, University of Toronto, Canada, 1999.

Guidotti, A. E.: A revision of the wasp genus Paniscomima (Hymenoptera: Rhopalosomatidae) and a proposal of phylogenetic relationships among species, Invertebr. Syst., 21, 297-309, https://doi.org/10.1071/IS04027, 2007.

Gurney, A. B.: Notes on the biology and immature stages of a cricket parasite of the genus Rhopalosoma, Proc. U.S. Nat. Mus., 103, 19-34, 1953.

Hamilton, W. D.: Evolution and diversity under bark, in: Diversity of insect faunas, edited by: Mound, L. A. and Waloff, N., Blackwell Scientific, Oxford, 154-175, 1978.

Heads, S. W.: A new pygmy mole cricket in Cretaceous amber from Burma (Orthoptera: Tridactylidae), Denisia, 26, 75-82, 2009.

Hood, J. D.: Notes on the life history of Rhopalosoma poeyi Cresson, Proc. Entomol. Soc. Wash., 15, 145-147, 1913 (Note: additional comments on the paper and rhopalosomatids by Rohwer appear on pages 147-148).

Lohrmann, V.: A revision of the Paniscomima of the African subregion with the description of two new species from Malawi and Tanzania (Hymenoptera: Rhopalosomatidae), Zoosyst. Evol., 87, 371-378, https://doi.org/10.1002/zoos.201100014, 2011.
Lohrmann, V. and Ohl, M.: World revision of the wasp genus Liosphex Townes, 1977(Hymenoptera: Rhopalosomatidae), Zootaxa, 2384, 1-43, 2010.

Lohrmann, V., Falin, Z. H., Bennett, D. J., and Engel, M. S. Recent findings of Olixon banksii in the Nearctic with notes on its biology (Hymenoptera: Rhopalosomatidae), J. Kans. Entomol. Soc., 87, 258-260, https://doi.org/10.2317/JKES130820.1, 2014.

Melo, G. A., Hermes, M. G., and Garcete-Barrett, B. R.: Origin and occurrence of predation among Hymenoptera: a phylogenetic perspective, in: Predation in the Hymenoptera: an evolutionary perspective, edited by: Polidori, C., Transworld Research Network, Trivandrum, 1-22, 2011.

Nel, A., Azar, D., and Hevret, S.: A new rhopalosomatid wasps [sic] in the Paleocene of France (Hymenoptera), Ann. Soc. Entomol. Fr., 46, 211-215, 2010.

Olmi, M., Xu, Z., and Guglielmino, A.: Descriptions of new fossil taxa of Dryinidae (Hymenoptera: Chrysidoidea) from Burmese amber (Myanmar), Acta Entomol. Mus. Nat. Pragae, 54, 703714,2014

O’Neill, K. M.: Solitary wasps: behavior and natural history, Cornell University Press, Ithaca, 2001.

Otte, D. and Alexander, R. D.: The Australian crickets (Orthoptera: Gryllidae), Acad. Nat. Sci. Phil. Monogr., 22, 1-477, 1983.

Perkins, R. C. L.: Some remarkable Australian Hymenoptera, Proc. Hawaiian. Entomol. Soc., 2, 27-35, 1908.

Ross, A., Mellish, C., York, P., and Crighton, B.: Burmese amber. In: Penney D (ed) Biodiversity of fossils in amber from the major world deposits, Siri Scientific Press, Manchester, 208-235, 2010.

Shi, G., Grimaldi, D. A., Harlow, G. E., Wang, J., Wang, J., Yang, M., Lei, W., Li, Q., and Li, X.: Age constraint on Burmese amber based on U-Pb dating of zircons, Cretaceous Res., 37, 155-163, https://doi.org/10.1016/j.cretres.2012.03.014, 2012.

Townes, H. K.: A revision of the Rhopalosomatidae (Hymenoptera), Contr. Amer. Entomol. Inst., 15, 1-34, 1977.

Walker, T. J.: Singing insects of North America. North American Crickets, available at: http://entnemdept.ufl.edu/Walker/ buzz/crickets.htm (last access: 15 May 2017), 2017.

Wilson, J. S., von Dohlen, C. D., Forister, M. L., and Pitts, J. P.: Family-level divergences in the stinging wasps (Hymenoptera: Aculeata), with correlations to angiosperm diversification, Evol. Biol., 40, 101-107, https://doi.org/10.1007/s11692-012-9189-0, 2013.

Zherikhin, V. V. and Ross, A. J.: A review of the history, geology and age of Burmese amber (Burmite), Bull. Nat. Hist. Mus. (Geology), 56, 3-10, 2000. 